\title{
Applicability of Ultrasonic Testing for the Determination of Volume Fraction of Particulates in Alumina-Reinforced Aluminum Matrix Composites
}

\author{
C.-K. Fang, ${ }^{*}$ R. L. Fang, ${ }^{\dagger}$ W. P. Weng, ${ }^{\ddagger}$ and T. H. Chuang $\$$ \\ *Department of Mechanical Engineering, China Institute of Technology, 245 Yen-Chu-Yuan Rd., \\ Sec. 3, Nankang, Taipei, Taiwan 115; 'Quality Control Division, Tang-Eng Iron Works Co., LTD., \\ Kaohsiung, Taiwan 812; ‡Loyalty Founder Enterprise, Co. LTD., Taoyuan, Taiwan 330; and \\ IInstitute of Materials Science and Engineering, National Taiwan University, Taipei, \\ Taiwan 106
}

An ultrasonic testing technique was employed to determine the volume fraction of alumina particulate reinforcement in 6061 aluminum matrix composites. This study was performed on various composites with $\mathrm{Al}_{2} \mathrm{O}_{3}$ nominal volume fractions of 10,15 , and $20 \%$. For comparison, other techniques were employed as well, including the Archimedes method, metallographic image analysis, X-ray diffraction, and acid dissolution. Observations indicated that ultrasonic testing and acid dissolution methods are more reliable than the other techniques, while ultrasonic testing is faster than the acid dissolution method. (C) Elsevier Science Inc., 1999. All rights reserved.

\section{INTRODUCTION}

A metal matrix composite (MMC) is normally fabricated using a ductile metal (e.g., aluminum, titanium, and nickel as the base material), which is reinforced by a ceramic (e.g., alumina, silion carbide, and graphite). Combining the metallic properties (good ductility and toughness) of the matrix with the ceramic properties (high strength, hardness, and elastic modulus) of the reinforcement, excellent material performance can be achieved, with the composite exhibiting high toughness, specific strength and stiffness, and good wear resistance. The MMC can also have low thermal and electric conductivity, and low sensitivity to temperature variation and thermal shock. Consequently, MMCs have recently engendered extensive interest from defense, aerospace, and automotive industries, and have become very promising engineering materials for other structural applications as well.
The MMC microstructures may be subdivided according to whether the reinforcement is in the form of continuous fibers, short fibers (whiskers), particulates, or platelets. Although continuous fiber- and whisker-reinforced MMCs have better material properties under certain conditions, the cost of raw materials and fabrication are relatively high compared to those for particulate-reinforced MMCs. Particulatereinforced MMCs are promising because of their homogeneous and isotropic material properties, low cost, and ability to be formed using conventional metal processing techniques.

The many factors related to the properties of MMCs include: (1) the properties of the base material [1,2], (2) the type, shape, dimensions, geometric arrangement, and volume fraction of the reinforcement [3-6], and (3) the wettability at the interface of the reinforcement and matrix, and the presence/absence of voids. Among these fac- 
tors, the volume fraction of reinforcement is particularly crucial because it is directly related to the strength, ductility, elastic modulus, and wear resistance of MMCs.

The most popular methods for determining the volume fraction of ceramic reinforcements include point counting, metallographic image analysis, and acid dissolution. A brief description of these and other techniques is described below.

\section{POINT COUNTING}

ASTM E562-83 gives the standard practice for performing the point-counting technique. The specimens need to be prepared using standard metallographic techniques. Using a square grid pattern, the number of grid intersections with the particles is counted. The result is obtained through dividing the number of grid intersections by the total number of the points in the grid. Averaged results from many sampling fields need to be taken to minimize measurement errors. The disadvantage of this method is, however, that it is time consuming.

\section{METALLOGRAPHIC IMAGE ANALYSIS}

Metallographic image analysis is accomplished by a computerized analysis of the digitized image on a computer monitor. The gray levels corresponding to the studied reinforcement are selected using a computer mouse. The regions with the selected gray levels are colored on the screen. Computing the area fraction of the colored regions by computer, the volume fraction of the reinforcement is obtained. This technique has the advantage of saving time, particularly for a fully automated system.

\section{ACID DISSOLUTION}

A composite specimen is immersed in an etching solution. The solution is selected such that the matrix is soluble in the solution, whereas the reinforcement is not. The retained insoluble ceramic reinforcement is dried and weighed. The calculated weight fraction of the reinforcement can be converted to a volume fraction.
Liang et al. [7] assessed the above three methodologies, viz.; point counting, metallographic image analysis, and acid dissolution. It was noted that the accuracy of these methods might be influenced by the differing matrix characteristics. To show the effects of the matrix and reinforcement composition on the results, two different matrices and two types of reinforcement were used in their study. It was found that a reasonably accurate volume fraction can be determined using all three techniques. For time-saving considerations, metallographic image analysis was preferred over the other two methods.

\section{ARCHIMEDES' METHOD}

This technique is based on the well-known Archimedes' principle. Let the weights of MMC in the air and in the water be $W_{a}$ and $W_{w}$, respectively, and the densities of the matrix material and the reinforcement be $d_{m}$ and $d_{r}$, respectively. The total volume of the composite is:

$$
V=\left(W_{a}-W_{w}\right) / d_{w},
$$

according to Archimedes' principle, where $d_{w}$ is the density of the water $\left(d_{w}=1 \mathrm{~g} /\right.$ $\mathrm{cm}^{3}$ ). If no voids are present in the MMC, the weight of the composite in the air is

$W_{a}=d_{m}\left(V-V_{r}\right)+d_{r} V_{r}$,

where $V_{r}$ is the total volume of the reinforcement. Solving Eqs. (1) and (2), the volume fraction of the reinforcement is obtained:

$$
\begin{aligned}
X_{r}= & V_{r} / V= \\
& \frac{d_{w} W_{a}}{\left(d_{r}-d_{m}\right)\left(W_{a}-W_{w}\right)}-\frac{d_{m}}{d_{r}-d_{m}}
\end{aligned}
$$

\section{X-RAY DIFFRACTION}

An X-ray diffraction technique is useful in the analysis of the elements present in the composite as well as in the determination of the percent phases present. According to the intensities of characteristic lines corresponding to the reinforcement material, the volume fraction of the reinforcement can be estimated. 


\section{ULTRASONIC TESTING}

Because of modulations of ultrasonic waves resulting from material variables, microstructures of materials influence ultrasonic wave propagation. Ultrasonic characterization according to the volume fraction of reinforcement in MMCs is thus possible. Because the variations in wave speed and energy losses are associated with the variations in microstructure, ultrasonic velocity and attenuation measurement can be used to estimate particle concentration in MMCs.

Using the ultrasonic technique, Delebarre et al. [8] estimated local particle concentration in MMCs through histogram processing techniques (based on the study of the mean value and standard deviation of the histograms). Measuring the longitudinal wave velocity at $100 \mathrm{MHz}$ frequency, they obtained an approximately linear slope for the velocity vs. the volume percent of $\mathrm{SiC}$ inclusions.

\section{EXPERIMENTAL PROCEDURE}

Alumina particulate-reinforced 6061 aluminum alloy composites $\left(\mathrm{Al}_{2} \mathrm{O}_{3} / \mathrm{Al}\right)$ were used in the present work. Different nominal volume fractions of the reinforcement in the composites were prepared, viz.; 10 , 15 , and $20 \%$. The MMCs were supplied by the Dural Aluminum Composites Co. in the United States. Their chemical compositions are listed in Table 1 . The as-cast materials in billet form of $200 \mathrm{~mm}$ in diameter were hot extruded into bars of $30 \mathrm{~mm}$ in diameter. Typical micrographs after extrusion are shown in Fig. 1.
In ultrasonic testing, the volume fraction of ceramic particles in the aluminum matrix composites was determined by measuring the ultrasonic wave speeds. A $5 \mathrm{MHz}$ straight-beam, single-crystal transducer was utilized to generate longitudinal stress waves. The thickness, $d$, of the MMC specimen and the time difference, $\Delta t$, between the transmitted and the back-reflected waves were measured. The wave speed in the $\mathrm{MMC}, v_{m m c}$, can be readily obtained using Eq. (4):

$v_{m m c}=2 d / \Delta t$.

If the volume fraction of the particles is $X_{p}$, the wave speed in the MMC can be expressed as:

$v_{m m c}=v_{m}\left(1-X_{r}\right)+v_{r} X_{r}$,

where $v_{m}$ and $v_{r}$ are wave speeds in the matrix material $(6061 \mathrm{Al})$ and in the reinforcement material $\left(\mathrm{Al}_{2} \mathrm{O}_{3}\right)$, respectively. Measuring $v_{m}$ and $v_{r}$, the volume fraction $X_{r}$ is readily obtained by solving Eq. (5).

To investigate the applicability of the ultrasonic testing method for the determination of the volume fraction of particulates, the results were compared with those obtained from other methods, including Archimedes' principle, metallographic image analysis, acid dissolution, and X-ray diffraction. The experimental procedures for these methods are described as follows.

\section{ARCHIMEDES' METHOD}

Fifteen specimens were cut for each composite. They were ultrasonically cleaned with acetone, and then weighed in $\operatorname{air}\left(W_{a}\right)$

Table 1 Chemical Compositions of the Aluminum Matrix in the Tested MMCs

\begin{tabular}{|c|c|c|c|c|c|c|c|c|c|}
\hline \multirow[b]{2}{*}{$M M C s$} & \multicolumn{9}{|c|}{ Elements (wt.\%) } \\
\hline & Si & $\mathrm{Fe}$ & $\mathrm{Cu}$ & $M n$ & $M g$ & $\mathrm{Cr}$ & $\mathrm{Zn}$ & $\mathrm{Ti}$ & $A l$ \\
\hline $10 \% \mathrm{Al}_{2} \mathrm{O}_{3} / \mathrm{Al}$ & 0.57 & 0.04 & 0.24 & $<0.01$ & 1.05 & 0.15 & 0.04 & 0.02 & Bal. \\
\hline $15 \% \mathrm{Al}_{2} \mathrm{O}_{3} / \mathrm{Al}$ & 0.48 & 0.05 & 0.22 & $<0.01$ & 0.90 & 0.14 & 0.05 & 0.01 & Bal. \\
\hline $20 \% \mathrm{Al}_{2} \mathrm{O}_{3} / \mathrm{Al}$ & 0.69 & 0.04 & 0.20 & 0.01 & 1.00 & 0.15 & 0.05 & 0.01 & Bal. \\
\hline
\end{tabular}



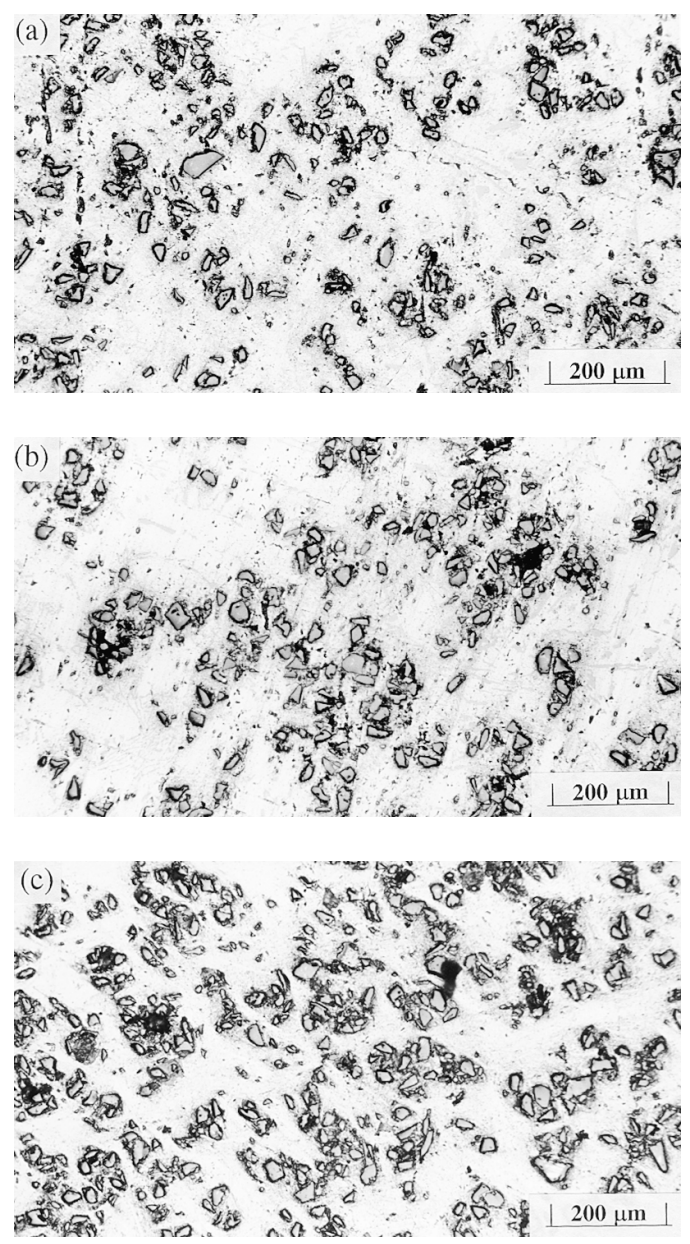

FIG. 1. Scanning electron micrographs of the polished surface on the MMCs with different particulate volume fractions: (a) $10 \%$; (b) $15 \%$; (c) $20 \%$.

and in water $\left(W_{w}\right)$. The densities of water, the matrix material (6061 Aluminum alloy), and the particles $\left(\mathrm{Al}_{2} \mathrm{O}_{3}\right)$ are 1, 2.7 and $3.986 \mathrm{~g} / \mathrm{cm}^{3}$, respectively. Substituting these values into Eq. (3), the volume fraction of the reinforcement, $X_{r}$, can be readily obtained.

\section{METALLOGRAPHIC IMAGE ANALYSIS}

The surface of the specimens was polished with emery paper. Final polishing was done using a rotary polishing cloth consisting of water-suspended $1 \mu \mathrm{m}$ alumina particles. After etching, the specimens were observed using an optical microscope connected to a computer. Using an image analyzer, several areas on the specimen were investigated. The image on the screen was divided into 64 gray levels. The gray level distribution contained two peaks, corresponding to the reinforcement particles and the matrix, respectively. A gray level threshold was chosen as the average gray level of the two peaks. The regions with the gray levels of interest were colored on the screen. The volume fraction of the ceramic phase was obtained through computation of the area fraction of the colored regions using an image analyzer.

Care must be taken to ensure that a flat surface is obtained, as different polishing rates can expose more or less of a given phase. Although the use of alumina as a polishing medium does present a difficulty because it has a similar hardness to the reinforcing phase, it was preferred over SiC. Wilson and Ball [9], for example, have found that abraded SiC particulates tend to become embedded in the Al 6061 alloy. However, if a satisfactory polish could be achieved with $\mathrm{SiC}$, a reduction in the standard deviation for the data would probably be obtained. In the present experiments, errors were considered relatively small as a result of using alumina, when compared with potential errors from poor differentiation between reinforcement and matrix in the MMCs.

\section{ACID DISSOLUTION}

Fifteen specimens were used for each MMC. Each specimen was weighed and denoted as $W_{a}$, before acid dissolution. After ultrasonically rinsing with acetone, each specimen was immersed and stirred in aqua regia, a mixture of three parts hydrochloric acid and one part nitric acid by weight. The specimen was first immersed in the solution and periodically stirred until the metal matrix was completely dissolved. After $6 \mathrm{~h}$, the solution was filtered through filter paper, initial weight, $W_{f}$. After filtering, the filter paper was dried in an oven, and then 
Table 2 Measured Volume Fractions (\%) of the Reinforcement Using Different Measuring Techniques

\begin{tabular}{lrcr}
\hline \multirow{2}{*}{\multicolumn{3}{c}{ Measuring techniques }} & \multicolumn{3}{c}{ Volume fractions of particles } \\
\cline { 2 - 4 } & $10 \% \mathrm{Al}_{2} \mathrm{O}_{3} / \mathrm{Al}$ & $15 \% \mathrm{Al}_{2} \mathrm{O}_{3} / \mathrm{Al}$ & $20 \% \mathrm{Al}_{2} \mathrm{O}_{3} / \mathrm{Al}$ \\
\hline Archimedes method & $7.10 \pm 0.055$ & $14.12 \pm 0.005$ & $16.52 \pm 0.002$ \\
Metallographic image analysis & $10.85 \pm 4.167$ & $17.23 \pm 3.566$ & $21.10 \pm 8.649$ \\
Acid dissolution & $9.38 \pm 0.191$ & $16.53 \pm 0.044$ & $19.09 \pm 0.319$ \\
Ultrasonic testing & $9.00 \pm 0.270$ & $15.29 \pm 0.351$ & $19.65 \pm 0.586$ \\
\hline
\end{tabular}

weighed, $W_{F}$. The weight of the $\mathrm{Al}_{2} \mathrm{O}_{3}$ particles is thus $W_{r}=W_{F}-W_{f}$, and the volume fraction of the particles [Eq. (6)] is:

$$
X_{r}=\frac{\frac{W_{r}}{3.986}}{\frac{W_{r}}{3.986}+\frac{W_{a}-W_{r}}{2.7}}
$$

\section{X-RAY DIFFRACTION}

The MMC specimens were sanded and polished before testing. An X-ray diffractometer was utilized to analyze the volume fraction of the reinforcement in the composites.

\section{RESULTS AND DISCUSSION}

Table 2 lists the measured results of the particulate volume fraction in three aluminum matrix composites using four different techniques, viz.; the Archimedes method, metallographic image analysis, acid dissolution, and ultrasonic testing. The standard deviation of the data is indicated. The results obtained from X-ray diffraction are not shown in Table 2 because they are semiquantitative. However, the results obtained from different techniques are discussed as follows.

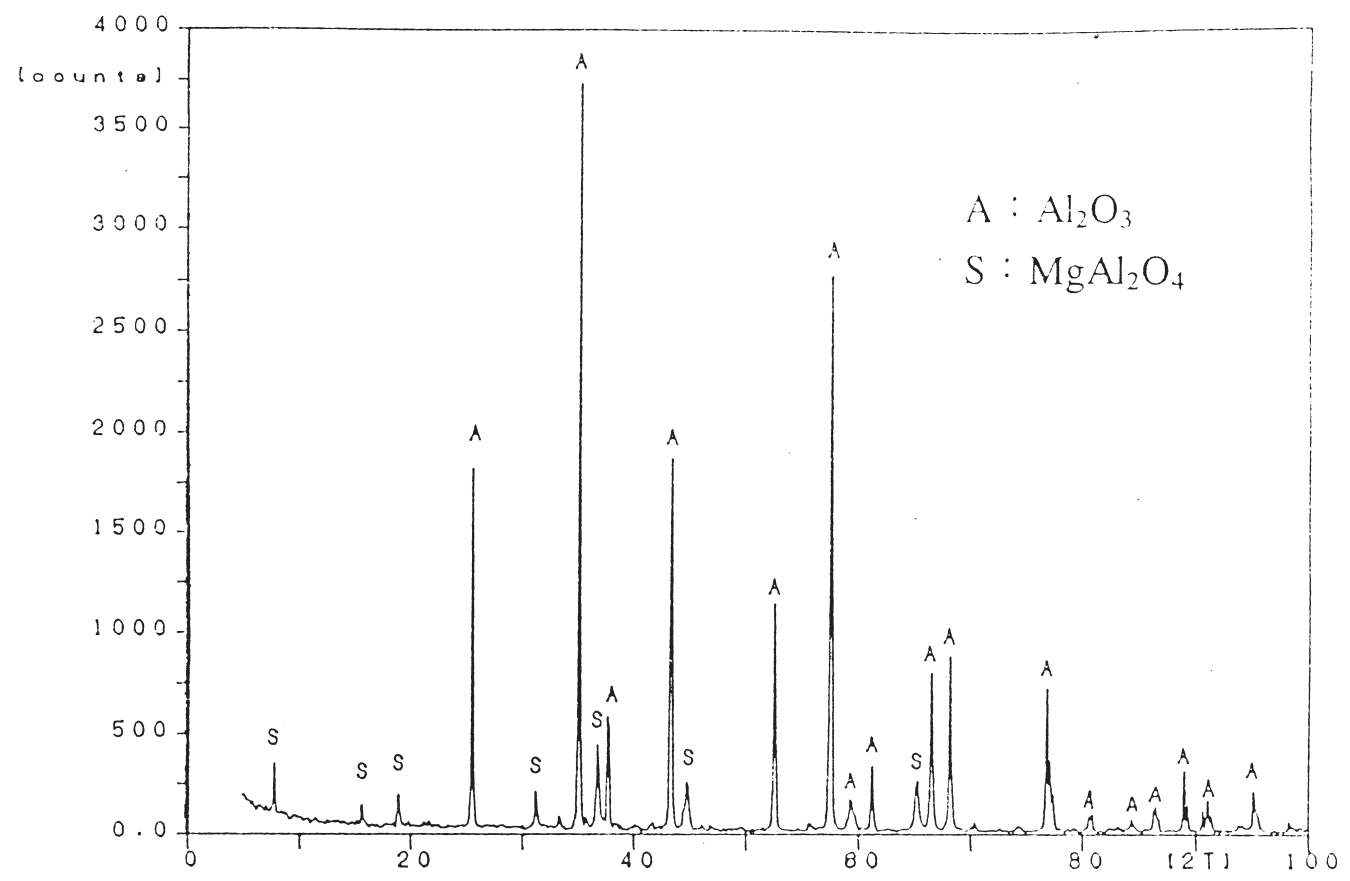

FIG. 2. X-ray diffraction spectrum of the powder obtained from acid dissolution. 


\section{THE ARCHIMEDES METHOD}

Although the measured results of the particulate volume fraction using the Archimedes method have very low standard deviations, the mean values are much lower than the nominal values, as indicated in Table 2 . This may be due to the porosity in the composites. If the total volume of the porosity is denoted as $V_{p}$, Eqs. (2) and (3) should be modified to Eqs. (7) and (8)

$$
\begin{aligned}
W_{a}= & d_{m}\left(V-V_{r}-V_{p}\right)+d_{r} V_{r}, \\
X_{r}= & \frac{d_{w} W_{a}}{\left(d_{r}-d_{m}\right)\left(W_{a}-W_{w}\right)}- \\
& \frac{d_{m}}{d_{r}-d_{m}}+\frac{d_{m}}{d_{r}-d_{m}} X_{p}
\end{aligned}
$$

where $X_{p}$ is the volume fraction of the porosity. Because the results for the Archimedes method shown in Table 2 were obtained from Eq. (3), they were underestimated by $X_{p} d_{m} /\left(d_{r}-d_{m}\right)$. Owing to the fact that the densities of the matrix material and ceramic particulate reinforcement are $d_{m}=$
2.7 and $d_{r}=3.986$, respectively, the error due to the existence of porosity is $2.1 X_{p}$. In other words, the error in the volume fraction of the reinforcement due to the existence of porosity is approximately twice the volume fraction of the porosity in the MMC. For a composite with 10\% reinforcement particles, the error percentage is $21 \%$ if the composite contains $1 \%$ porosity.

Overall, this method may result in very large errors due to the porosity in composites. In addition, if any of the pores are surface connected, water may progressively enter the porosity network during weighing, giving variable readings. A possible solution to the problem caused by surfaceconnected pores is to coat the sample with a thin layer of a lacquer impervious to water [10]. As for controlling internal porosity, no solution is available thus far.

Despite the advantages of speed, ease, and minor errors in the operation process (low standard deviations), this technique is not reliable if the tested composite contains pores. Unfortunately, porosity is inevitable

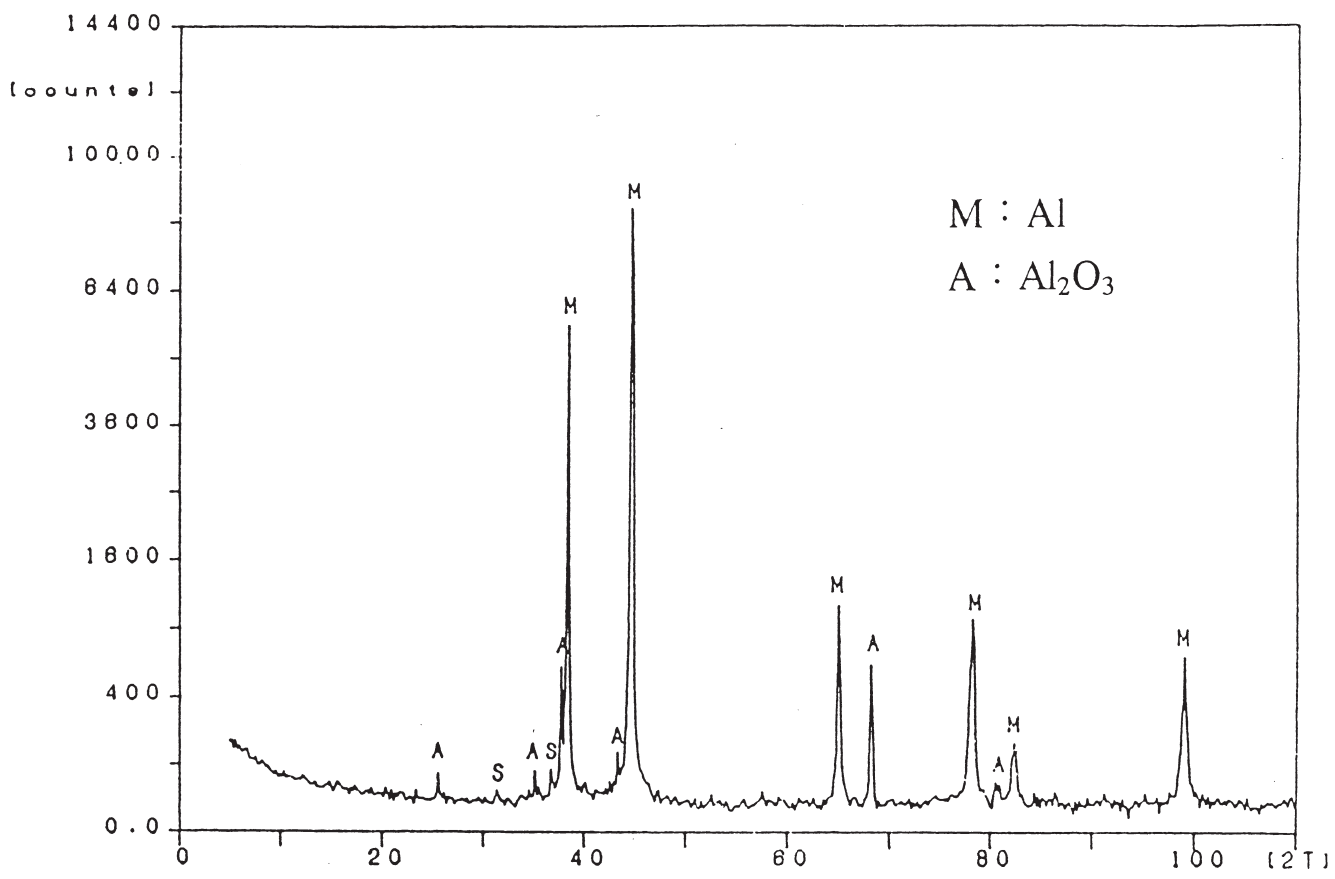

FIG. 3. X-ray diffraction spectrum of the $10 \% \mathrm{Al}_{2} \mathrm{O}_{3} / \mathrm{Al}$ composite. 


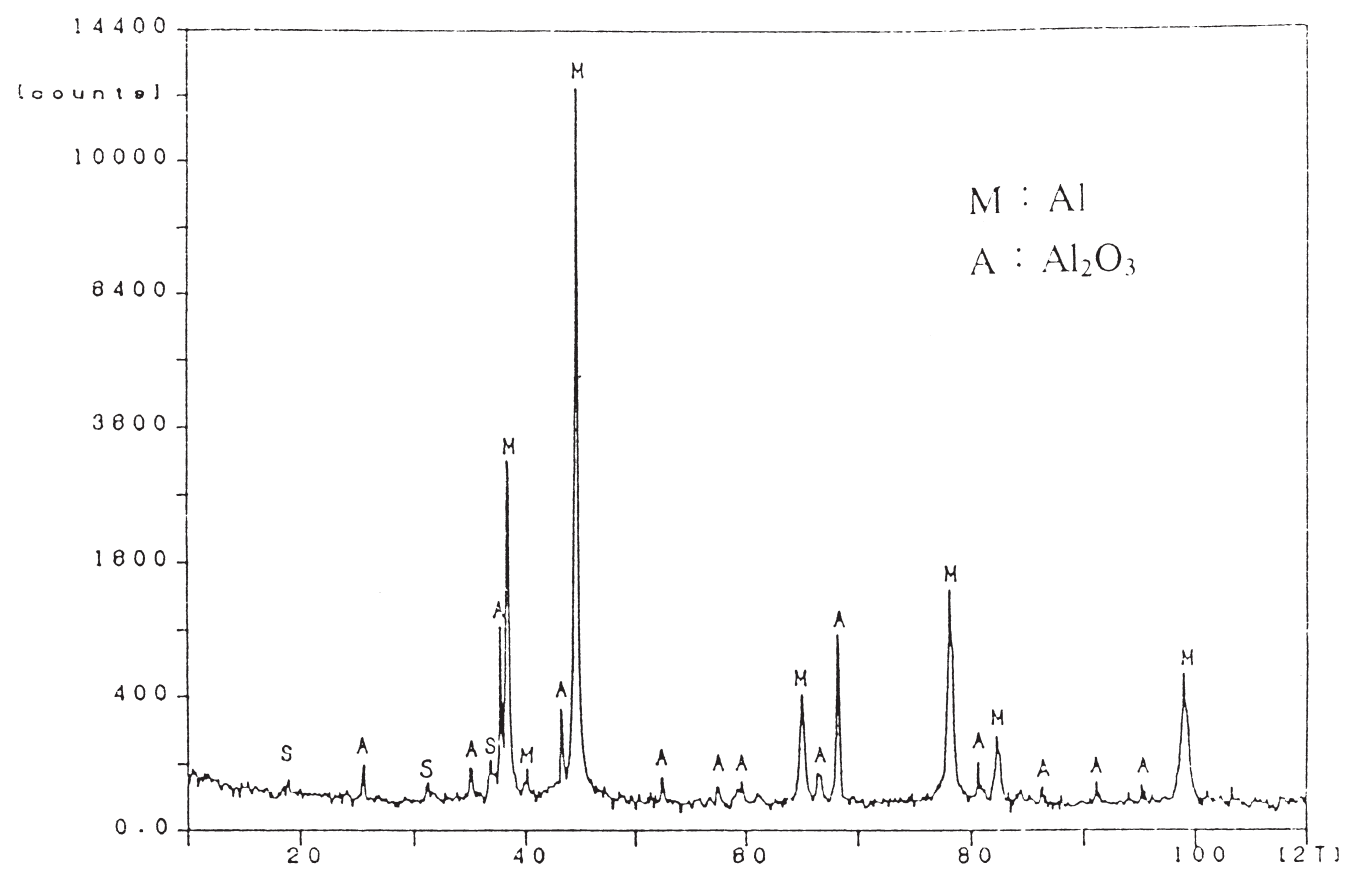

FIG. 4. X-ray diffraction spectrum of the $15 \% \mathrm{Al}_{2} \mathrm{O}_{3} / \mathrm{Al}$ composite.

for most of the metal matrix composites, particularly for those fabricated by casting. The Archimedes principle is, consequently, not very suitable, in practice, for the determination of the volume fraction of the reinforcement in composites.

\section{METALLOGRAPHIC IMAGE ANALYSIS}

Because the image analyzer can mistakenly identify impurities (e.g., pores and inclusions) as reinforcement particles, the measured volume fractions are larger than the nominal values, as illustrated in Table 2 . In addition, large standard deviations are observed in the results. Unless the image of the reinforcement contrasts well with that of the matrix, it is difficult to define the range of the gray levels to be selected as the reinforcement. Unfortunately, a good contrast between the reinforcement and the matrix is normally unobtainable in most of the metal matrix composites. As a result, the volume fraction is usually estimated with a large error. Despite its advantage of saving time, using image analysis to determine the reinforcement volume fraction in MMCs is sometimes not very reliable.

\section{ACID DISSOLUTION}

The measured results using the acid dissolution method are very close to the nominal values, as indicated in Table 2 . Theoretically, the acid dissolution technique can allow a precise measurement of the volume fraction of the reinforcement. In practice, some errors can occur due to improper operations. For instance: (1) the ceramic particles are easily lost during filtering; (2) the filtered reinforcement will be overweighed if the filter paper is not washed by distilled water during filtering, and the acid thus remains on the filter paper; (3) the particles will be overweighed if the filter paper is not fully dried after filtering. These problems can be overcome by taking special care during the experimental process. Also, the results will be influenced by the formation of interfacial products due to the reac- 


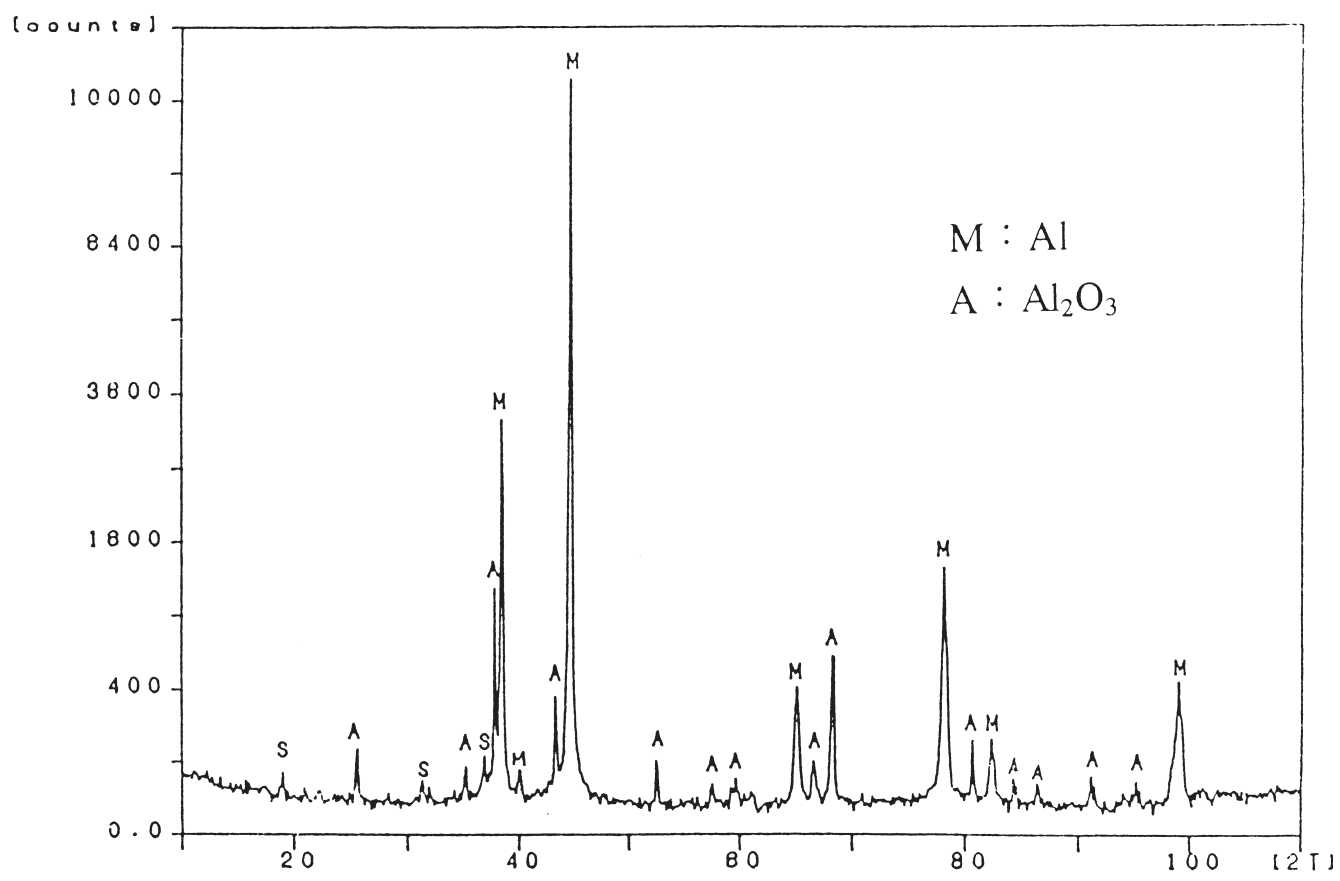

FIG. 5. X-ray diffraction spectrum of the $20 \% \mathrm{Al}_{2} \mathrm{O}_{3} / \mathrm{Al}$ composite.

tion of the reinforcement and the matrix materials. Figure 2 shows the X-ray diffraction spectrum of the powder obtained from acid dissolution. It was found that the powder contains an interfacial product $\mathrm{MgAl}_{2} \mathrm{O}_{4}$ due to the reaction of the $\mathrm{Al}_{2} \mathrm{O}_{3}$ particles and the aluminum matrix. The accuracy of this method depends on the relative amount of interfacial product to that of reinforcement particles. Overall, this method is relatively reliable, with both accurate mean values and low standard deviations, as long as the amount of interfacial product is negligibly small and the measuring process is conducted with special care.

\section{X-RAY DIFFRACTION}

The X-ray diffraction spectra of the tested MMCs are illustrated in Figs. 3-5. The characteristic lines (sharp intensity maxima) of $\mathrm{Al}$ and $\mathrm{Al}_{2} \mathrm{O}_{3}$ appear in each spectrum. Table 3 shows the relative intensities of some major $\mathrm{Al}_{2} \mathrm{O}_{3}$ peaks. It was found that the relative intensity of $\mathrm{Al}_{2} \mathrm{O}_{3}$ peaks somehow increases with the increasing volume fraction of reinforcement, although some exceptions are observed. A mathematical function for the relationship between the spectrum and the particulate concentration is, however, not available. Consequently, the X-ray diffraction method can provide

Table 3 Relative Intensities of the $\mathrm{Al}_{2} \mathrm{O}_{3}$ Peaks in the Spectra of Three MMCs in This Study

\begin{tabular}{ccccccr}
\hline \multirow{2}{*}{$M M C s$} & $25.54^{\circ}$ & $35.14^{\circ}$ & $37.80^{\circ}$ & $43.36^{\circ}$ & $68.15^{\circ}$ & $80.63^{\circ}$ \\
\cline { 2 - 6 } & $0.2 \%$ & $0.4 \%$ & $3.6 \%$ & $0.9 \%$ & $6.2 \%$ & $1.0 \%$ \\
$10 \% \mathrm{Al}_{2} \mathrm{O}_{3} / \mathrm{Al}$ & $1.1 \%$ & $7.1 \%$ & $7.3 \%$ & $2.0 \%$ & $8.5 \%$ & $0.6 \%$ \\
$15 \% \mathrm{Al}_{2} \mathrm{O}_{3} / \mathrm{Al}$ & $0.7 \%$ & $0.7 \%$ & $10.2 \%$ & $2.7 \%$ & $8.8 \%$ & $1.3 \%$ \\
$20 \% \mathrm{Al}_{2} \mathrm{O}_{3} / \mathrm{Al}$ & $0.7 \%$ & &
\end{tabular}


Table 4 Comparison of the Techniques Used in the Present Study to Determine the Volume Fraction of Particulates in $\mathrm{Al}_{2} \mathrm{O}_{3} / \mathrm{Al}$ Composites

\begin{tabular}{|c|c|c|}
\hline Testing methods & Advantages & Disadvantages \\
\hline Archimedes method & $\begin{array}{l}\text { Fast, easy in operation, } \\
\text { low standard deviations }\end{array}$ & Very susceptible to porosity \\
\hline Metallographic image analysis & Fast & $\begin{array}{l}\text { High contrast between reinforcement } \\
\text { and matrix is required. } \\
\text { Large standard deviations }\end{array}$ \\
\hline Acid dissolution & Reliable & $\begin{array}{l}\text { Time-consuming; } \\
\text { need trained operators }\end{array}$ \\
\hline X-ray diffraction & Convenient & Semiquantitative results only \\
\hline Ultrasonic testing & Fast, reliable & Susceptible to large pores \\
\hline
\end{tabular}

only a semiquantitative result for the volume fraction of the reinforcement in MMCs.

\section{ULTRASONIC TESTING}

Solving Eq. (5), the volume fractions of the reinforcement were obtained, and are given in Table 2. The calculated results for both ultrasonic testing and acid dissolution are very close to the nominal values, with both accurate mean values and low standard deviations.

Ultrasonic testing is reliable for the determination of particle concentration in MMCs if good wetting conditions exist in the interface of the reinforcement and matrix. However, some problems may occur if large pores exist in the MMCs. The ultrasonic waves will be scattered by the pores, resulting in noise on the screen of the ultrasonic tester. The sound pressure, $P_{F}$, of the reflected waves from a spherical pore can be expressed as:

$P_{F}=P_{o} \frac{A d}{4 \lambda x^{2}} \quad\left(d<\frac{0.4 \lambda x}{D}\right)$,

where $P_{o}$ is the transmitted sound pressure from the transducer, $A$ and $D$ are the crosssectional area and the diameter, respectively, of the transmitter (piezoelectric element) in the transducer, $\lambda$ is the wavelength, and $x$ is the distance between the piezoelectric element and the pore. Minimizing the reflected stress waves from pores requires the use of a smaller transducer and an ultra- sound of lower frequency, according to Eq. (9). In general, $P_{F} / P_{o} \leqq 5 \%$ is acceptable. In the present study, a $5 \mathrm{MHz}$ transducer with a piezoelectric element of $7 \mathrm{~mm}$ in diameter was utilized. The longitudinal wave speed and wavelength in the aluminum are $6320 \mathrm{~m} / \mathrm{s}$ and $1.264 \mathrm{~mm}$, respectively. If a pore exists at $x=10 \mathrm{~mm}$ from the piezoelectric element, the diameter of the pore should not exceed $0.66 \mathrm{~mm}$.

\section{CONCLUSIONS}

Table 4 gives a comparison of the five techniques used in the present study to determine the volume fraction of reinforcement in MMCs. The results for acid dissolution and ultrasonic testing have accurate mean values and low deviations. As for time-saving considerations, the latter is preferred. Overall, ultrasonic testing is a reliable and fast technique if the pores in the MMCs are not too large in size.

\section{References}

1. J. England and I. W. Hall: On the effect of the strength of the matrix in metal composites. Scripta Met. 20:697 (1986).

2. C. M. Friend: The effect of matrix properties on reinforcement in short alumina fibre-aluminum metal matrix composites. J. Mater. Sci. 22:3005 (1987).

3. T. C. Dragone and W. D. Nix: Geometric factors 
affecting the internal stress distribution and high temperature creep rate of discontinuous fiber reinforced metals. Acta. Met. 38:1941 (1990).

4. D. M. Stefanescu, A. Moitra, A. S. Kacar, and B. K. Dhindaw: The influence of buoyant forces and volume fraction of particles on the particle pushing/entrapment transition during directional solidification of $\mathrm{Al} / \mathrm{SiC}$ and $\mathrm{Al} / \mathrm{Graphite}$ composites. Metall. Trans. A 21A:231 (1990).

5. J. B. Brockenbrough, S. Suresh, and H. A. Wieneck: Deformation of metal-matrix composites with continuous fibers: Geometrical effects of fiber distribution and shape. Acta. Met. 39:735 (1991).

6. D. L. McDaniels: Analysis of stress-strain, fracture, and ductility behavior of aluminum matrix composites containing discontinuous silicon carbide reinforcement. Metall. Trans. A 16A:1105 (1985).
7. X. Liang, J. C. Earthman, J. Wolfenstine, and E. Lavernia: A comparison of techniques for determining the volume fraction of particulates in metal matrix composites. Mater. Char. 28:173-178 (1992).

8. C. Delebarre, I. Baquet, C. Bruneel, J. M. Rouvaen, and Z. Derouiche: Quantitative characterization of metal matrix composites using histogram processing techniques. NDT $\mathcal{E}$ E Int. 25:195-200 (1992).

9. S. Wilson and A. Ball: Advances in Composite Tribology, K. Friedrich, ed., Elsevier, New York, pp. 311366 (1993).

10. T. W. Clyne and P. J. Withers: An Introduction to Metal Matrix Composites. Cambridge University Press, New York, p. 441 (1993).

Received August 1998; accepted December 1998. 